\title{
Development and Simulation of an Anaerobic Bioreactor of a Solid Domestic Waste Landfill in Order to Forecast the Leachate Transportation and Safe Salt Accumulation in the Landfill Body
}

\author{
L.A. Shirkin, T.A. Trifonova and S.I. Roshchina \\ Vladimir State University, Russia, 600000, Vladimir, Gorky Street, 87.
}

DOI: http://dx.doi.org/10.13005/bbra/1893

(Received: 30 September 2015; accepted: 19 November 2015)

\begin{abstract}
The goal of the study was to evaluate the stability of the natural-technical system of an SDW landfill through the development of an imitation model of an anaerobic bioreactor of the SDW landfill and computational simulation of the processes of formation, transportation and accumulation of contaminated leachate during the infiltration of the brines of liquid effluents for the purposes of geo-ecological substantiation of safe disposal of "tails" (non-utilizable highly concentrated liquid effluents) at the landfill. With the example of one of the SDW landfills of the Vladimir Region we came up with new solutions and obtained new data: 1) on the time during which the maximum increase of salt concentration in the drainage system leachate will be detected after the start of the concentrate infiltration into the landfill body; 2) on the limiting volumes (amounts) of non-utilizable liquid effluents disposal, which the landfill body can take; 3) on the forecasting conditions of salts accumulation in the landfill body and in the leachate.
\end{abstract}

Key words: Anaerobic bioreactor, SDW landfill, leachate, mineralization, migration, simulation, safe disposal.

As of today, there are no models that describe the processes of formation, transportation and accumulation of contaminated leachate and allow forecasting the composition of filtration waters and biodegradation of an organic substance under the conditions of an anaerobic reactor of the SDW landfill. One of the reasons is the inconsistency of its composition, which is determined by the SDW morphological composition, the time of residence in the landfill body, as well as the dilution degree by precipitation.

The developed mathematical models of

* To whom all correspondence should be addressed. anaerobic systems usually presuppose total mixing of the reaction space and are directed mainly on the evaluation of the generated biogas volumes. The ADM1 imitation model created under the auspices of the International Water Association (IWA, 2002) as a result of a 4-year partnership of the international expert group on anaerobic processes, control and mathematical simulation is also designed for the analysis of processes with complete mixing. First distributed models of anaerobic process have been created relatively recently. A modern SDW landfill is considered to be an anaerobic bioreactor. This will require developing of a modern mathematical model of such a bioreactor. For this purpose, it is necessary to take into account complex physical, physical and chemical, and biological processes occurring deep 
in the waste mass. First steps in the creation of the distributed model were taken in the Institute of Water Problems of the Academy of Sciences of the Russian Federation (Vavilin et al, 1993, 2009). The goal of constructing a model is to analyse the behaviour of microorganism communities degrading organic substances. The mathematical model presented as a system of non-linear equations in partial derivatives was solved computationally with the use of modern mathematical packages (MATHLAB and FEMLAB). It considered such a process as the microbiological oxidation of methane in the aerobic zone. This model is highly complex, as the search of numerous coefficients is necessary, including the diffusion coefficient of acids, biomass and $\mathrm{Na}$, as well as the inhibition constants of biochemical reactions. The model offers the means to forecast the leachate composition by the indicator of organic acids concentrations and does not allow forecasting changes in the leachate composition in case of the disposal of salt concentrate (brine) into the landfill body. That is why instead of complex bulky structural models it is necessary to apply simplified models of anaerobic systems including forecasting of the leachate composition, for example, by such an indicator as general mineralization. However, existing domestic and foreign computational models allow forecasting the volume of the formed leachate but not its qualitative indicators.

The "ROCHEM" and "PALL-ROCHEM" companies offered and approved the technological purification scheme of the filtration waters of SDW landfills with the use of plane-parallel reverse osmosis membrane modules. The system of reverse osmosis is organized in three stages, but the concentrate with reverse osmotic membrane modules (5-10\% from the general volume of original water) is returned to the landfill body. At the same time, it was shown that the most secure method is the method with the consequent binding into insoluble blocks of the residual concentrate and its disposal in the landfill body.

In the recent past, the costs of disposing the concentrate were estimated as quite high. Some systems worked on a number of landfills, using evaporation, drying of the concentrate or its binding by various binding agents, followed by burial of dry insoluble products in the body of the landfill itself. Currently, the most promising method of treating concentrates is their controlled utilization in the body of the landfill, which is not only the cheapest way of disposing the concentrate, but it supposedly improves the biochemical processes in organic residues and accelerates the immobilization and destructurization of organic compounds.

The goal of the study was to evaluate the stability of the natural-technical system of the solid waste landfill through the development of an imitation model of an anaerobic bioreactor of the SDW landfill and computational simulation of the formation, transportation and accumulation processes of contaminated leachate during the infiltration of liquid effluents brines for the purposes of geo-ecological substantiation of safe disposal of "tails" (non-utilizable highly concentrated liquid effluents) at the landfill.

The relevance and scientific novelty of the problem to be solved are due to: 1) nonlinearity and instability of the processes of organic matter biodegradation determined by the leachate composition and implemented via different mechanisms, including the insufficiently studied mechanisms of product-substrate inhibition; 2) the need to test the hypothesis on the possibility of safe projectable accumulation of salts in the landfill body as a result of using SWD landfills for disposing liquid effluents brines; 3 ) the lack of domestic and foreign computational models capable of forecasting not only the volume of the resulting leachate, but also the indicators of its quality; 4) the dependence of the selection of the of the leachate purification scheme on the composition and mineralization of the leachate, as many of the used neutralization methods are limited by the upper permissible concentration of contamination, the content of which often exceeds permissible values in real conditions.

\section{METHODS}

The simulation object is the solid domestic waste landfill. The model approbation was conducted on the example of the Maryinka SDW landfill (the Vladimir Region). The formation and transportation processes of the contaminated leachate with the concentrate infiltration in the SDW landfill mass from the surface layers to the 
drainage system are considered a research and simulation object. As the leachate is a mineralized solution with total salt content up to $14-17 \mathrm{~g} / \mathrm{dm}^{3}$, and the concentrate introduced into the landfill body is characterized by significant mineralization of dissolved organic substances, the output parameters of the developed model act as indicator of the total mineralization in the leachate.

The analysis of the processes in the landfill body presented in several publications allows making up a kinetic scheme of waste biodestruction and leachate formation in the landfill body. The formation processes of the leachate mineralization in the landfill body can be presented as a block diagram (Fig. 1).

For the purposes of mathematical simulation, waste biodestruction in the landfill body can be simplistically presented as a process occurring in 2 stages: 1 ) dissolution, hydrolysis of organic compounds, acidogenesis; 2) methanogenesis.

The first stage consists of the processes of dissolution, hydrolysis of the waste organic substance and acidogenesis, which occur continuously. At this stage, two groups of bacteria take part in the processing of the available organic substance contained in the solid phase of waste. The first group transforms complex organic substrates into fatty acids, and then into butyric, propionic and lactic acids (substage of dissolution and hydrolysis of organic compounds); the second group transforms these organic acids into the acetic acid, hydrogen and carbon dioxide (substage of acidogenesis). At this stage, the hydrolysis processes are limiting. On a typical landfill, the anaerobic oxidation process results in the formation and accumulation of high concentrations of fatty acids, which determine the indicator of total mineralization of the leachate.

The second stage - methanogenesis occurs only when molecular oxygen is exhausted and carbon dioxide is accumulated. In practice, methanogenesis is mostly implemented in the mesophilic environment, as the intensity of biogas release in this medium is not as sensitive to temperature fluctuations of the substrate. Methanogenic bacteria complete the biodestruction of materials using molecular hydrogen, carbon dioxide and carbon monoxide gases and lower organic acids as well, which are released during the fermentation processes.

The important biochemical feature of waste biodestruction is that at all stages of waste biodestruction the leachate takes in carboxylic acids and their salts, primarily acetic acid, which determine the physicochemical properties of the leachate to a large extent.

The formation process of leachate mineralization in the landfill body can be described as a system of differential equations of the first order in partial derivatives:

$$
\left\{\begin{array}{l}
\frac{\partial C}{\partial t}=-v_{l} \frac{d C}{d z}-\frac{\rho}{Q} \cdot \frac{\partial S}{\partial t}+\frac{\rho}{Q} \cdot k_{1} W-k_{2} C \\
\frac{\partial S}{\partial t}=K \frac{\partial C}{\partial t} \\
\frac{\partial W}{\partial t}=-k_{1} W
\end{array}\right.
$$

where $z$ is a coordinate, depth in the layer of waste, $\mathrm{m}$; $t$ - a moment of time, days; $C(z, t)$ the mineralization function of the leachate or the total concentration of dissolved substances in ionic and colloidal forms in the liquid phase of the leachate, $\mathrm{mg} / \mathrm{l} ; S(z, t)$ - function of the total con-centration of dissolved substances that passed into the solid waste phase and are in the sorbed state, $\mathrm{mg} / \mathrm{kg} ; W(z, t)$ - organic waste material content available for biological destruction in the solid phase, $\mathrm{kg} / \mathrm{kg}$; $K$ - a coefficient of the specific waste capacitance by dissolved substances or the coefficient of dissolved substances distribution between the liquid and solid phases, $\mathrm{m}^{3} / \mathrm{kg} ; v_{1}$ flo-w rate of the leachate in the waste mass, $\mathrm{m} /$ day; $r$ - the density of wet waste in the landfill array, $\mathrm{kg} / \mathrm{m}^{3} ; \mathrm{Q}$ - the relative proportion of pores (voids) being filled by the leachate in the waste of the landfill body, $\mathrm{m}^{3} / \mathrm{m}^{3} ; k_{1}$ - the constant of reactions rate in the phase of hydrolysis and acidogenesis, days ${ }^{-1} ; k_{2}$ - the constant of reactions rate in the phase of methanogenesis, days ${ }^{-1}$.

The first differential equation in the system describes the formation processes of the leachate mineralization or the total concentration of dissolved substances and is based on the model of ideal displacement, but with the sorption/ desorption processes, as well as kinetics of the 
two phases of waste biodestruction being taken into account. The second differential equation reflects the kinetics of the processes of the mechanical, physical, chemical and biological sorption/desorption in relation to the dissolved components of the leachate and redistribution between the liquid and solid phases in the landfill body. This equation has been used by researchers to forecast the migration of heavy metals salts in the soil profile in view of the sorption processes. The third differential equation describes the kinetics of content changes in the solid phase of organic material waste available for biological destruction.

The kinetics of the first order is traditionally used to describe the biodestruction of organic substances; during the development of the mathematical model, the following processes have been taken into account in the terms of differential equations (Fig. 1):

$$
-v_{t} \frac{\partial C}{\partial z}-\text { is a term of the differential }
$$

equation that describes the movement of the dissolved substance with the leachate in the landfill body from the uppermost layers of waste to the drainage system;

$$
-\frac{\rho}{Q} \cdot \frac{\partial S}{\partial t}-\text { is a term of the differential }
$$

equation that takes into account the sorption/ desorption processes in respect to the dissolved components of the leachate;

$$
\frac{\rho}{Q} \cdot k W_{-} \text {is a term of the differential }
$$

equation which takes into account the processes of dissolution and hydrolysis of organic compounds and acidogenesis, which culminate in the release of fatty and regular carboxylic acids and their salts into the leachate;

$-\mathrm{k}_{2} \mathrm{C}$-is a term of the differential equation that describes the processes of methanogenesis. In view of the proposed kinetic scheme of waste biodestruction, the original data on the example of the Maryinka landfill are summarized and specified for the proposed mathematical model, including the following data on: 1) climatic conditions and elements of the water balance of the landfills (amount of precipitation and the ratio of the volumes of the leachate/precipitation); 2) physical parameters of the waste situated in the landfill array (waste density and moisture in the landfill array); 3) on the physicochemical characteristics of the leachate and concentrate, formed after reverse osmosis desalination (mineralization); 4) hydrodynamic conditions encountered in the landfill array (coefficient of waste filtration); 5) optimal parameters of waste biodestruction in the SDW landfill array (the initial content of organic matter available to biological destruction, waste moisture level and constants of the methanogenesis reaction rate).

In general, for SDW landfills situated in the region with a moderately continental climate, the ratio of leachate/precipitation volumes oscillates in the range from 0.511 to 0.539 .

The calculation of the relative proportion of pores (voids) filling of the leachate may be carried out based on the system of algebraic equations used to describe moisture indicators of soils:

$$
\left\{\begin{array}{l}
\rho_{s}=\frac{\rho}{1+w} \\
P=1-\frac{\rho_{s}}{\rho_{t}} \\
e=\frac{P}{1-P} \\
Q=\frac{w \cdot \rho_{s}}{e \cdot \rho_{m}}
\end{array}\right.
$$

The first equation of the system is the dependence of the dry waste density (skeletal density) on the density $(\sigma)$ and moisture (w) of waste in the landfill array. The second equation is the porosity calculation through the skeletal density and the true density of the waste. The third equation is the calculation of the void ratio (e) of waste through the porosity $(P)$. The fourth equation is the calculation of the relative proportion of pores (voids) being filled with the leachate in the landfill body waste $(Q)$. After transformations, we obtain a single analytic formula for the $Q$ parameter:

$$
Q=\frac{w \rho^{2}}{(1+w) \rho_{m}\left(\rho_{t}-\rho+w \cdot \rho_{t}\right)}
$$


The following data is taken as the initial data: waste moisture after compaction at the SDW landfill $w=0.55$; wet waste moisture in the landfill array $\mathrm{r}$ $=670 \mathrm{~kg} / \mathrm{m}^{3}$; true density of waste $\mathrm{r}_{t}=860 \mathrm{~kg} / \mathrm{m}^{3}$; leachate density $r_{m}=1000 \mathrm{~kg} / \mathrm{m}^{3}$. After the calculation we obtain that the relative proportion of pores (voids) filling by the leachate in waste of the landfill body is $Q=0.24$.

The constant of sorption equilibrium or the distribution coefficient of dissolved substances between the liquid and solid phases of waste in the developed model in the absence of experimental data is taken by default as $K=1.7 \mathrm{l} /$ $\mathrm{kg}$, which corresponds to the conservative estimate of sorption equilibrium, taking into account the exchange nature of the sorption of dissolved substances from solutions.

On the basis of the biochemical model of waste biodestruction (Fig. 1, 2), the kinetic model can be developed to forecast the change in the leachate mineralization in respect to time.

Flow formation of dissolved substances during waste degradation can be described by two consecutive reactions that correspond to two phases of waste biodestruction. That is the change in the leachate composition in respect to time can be determined based on the kinetic equation of a consequent reaction of the first order.

$$
W \longrightarrow \stackrel{k_{1}}{\longrightarrow} C \stackrel{k_{3}}{\longrightarrow} P
$$

In the considered kinetic scheme $k_{1}$ is a rate constant of the reaction in the phase of dissolution, hydrolysis of an organic substance and acidogenesis, $k_{2}$ is the rate constant in the methanogenesis phase.

$$
\left\{\begin{array}{l}
\frac{d W}{d t}=-k_{1} W \\
\frac{d C}{d t}=\frac{\rho}{Q} k_{1} W-k_{2} C
\end{array}\right.
$$

Concentration of substances with respect to leachate mineralization $C(t)$ gives a solution to this system:

$$
C(t)=\frac{\rho}{Q} W_{0} \cdot \frac{k_{1}}{k_{2}-k_{1}}\left[e^{-k_{1} t}-e^{-k_{2} t}\right]
$$

where $W_{0}$ is the initial content of an organic substance waste in the solid phase; this substance waste is available for biodestruction and equal to the amount of the cellulose-containing fraction in $1 \mathrm{~kg}$ of SDW, determined based on the known morphological composition of waste.

As the constant of reaction rate in the methanogenesis phase for the conditions of the moderately continental climate is determined relatively accurately $-k_{2}=0.07$ year $^{-1}$, and the peak of leachate mineralization falls within $t_{\max }=5$ years after the beginning of landfill exploitation, then the constant of the reaction rate in the phase of dissolution processes, hydrolysis of organic substances and acidogenesis can be found by solving an algebraic equation in respect to $\mathrm{k}_{1}$.

Hence, for the mathematical simulation we can take the following values of the coefficients:

$$
K=1.7 \times 10^{-3} \mathrm{~m}^{3} / \mathrm{kg} ; k_{1}=1.347 \times 10^{-4} \text { year }^{-1}
$$

$=3.688 \times 10^{-7}$ day $^{-1} ; k_{2}=0.070$ year $^{-1}=1.917 \times 10^{-4}$ day $^{-1} ; W_{0}=0.3 \mathrm{~kg} / \mathrm{kg}$.

The average residence time of the introduced concentrate salts can be evaluated after the analytical transformations of the differential equations system by using the formula:

$$
\tau=\frac{H}{v_{b}}\left[\frac{K \rho_{m}(1+w)\left(\rho_{t}-\rho+w \rho_{t}\right)}{w \rho}+1\right]
$$

The $\tau$ parameter gives the time information on the time after which the increase in the salts concentration of the drainage system leachate will be detected after the start of the concentrate infiltration into the landfill body.

The first stage of the waste disposal complex near the village of Maryinka of the Kameshkovsky District was put into operation. Environmental protection measures are envisaged for the facility operation: the use of a geomembrane made of durable plastic that prevents the penetration of harmful products into the soil and aquifers; construction of facilities for the collection and purification of leachate seeping through the waste; the use of technologies of waste storage with the waste compaction and overturning with soil, which prevent rodents, odours and dispersal of light fractions of waste (Fig. 1).

As of today, more than 4 thousand of cubic meters of sorted waste have been delivered to the waste disposal system for a test run (Fig. 2).

The leachate formed on the card is pumped into special storage containers and will 
be poured over the waste during a fire hazardous period.

The average height of the waste layer in the model is taken equal to $H=5 \mathrm{~m}$. The gradient value of the filtration flow is taken as $51.1 \%$ from the precipitation amount. The default average density of wet waste in the landfill is taken equal to $670 \mathrm{~kg} / \mathrm{m}^{3}$, and the true density of domestic waste $-860 \mathrm{~kg} / \mathrm{m}^{3}$. Waste moisture at the landfill after compaction is taken equal to 0.55 . The filtration coefficient value used in the computation is taken equal to the lower limit of the $90 \%$ confidence interval in order to distribute experimental values of the filtration coefficient or $0.277 \mathrm{~m} /$ day. Since the initial content of the solid phase organic substance waste available for biological destruction equals to the amount of the cellulosecontaining fraction in $1 \mathrm{~kg}$ of SDW determined based on the known morphological composition of waste, then the amount of the cellulosecontaining faction by default is taken equal to $300,000 \mathrm{mg} / \mathrm{kg}$. For the purposes of mathematical simulation, waste biodestruction in the landfill body can be considered as a process occurring in two consequent stages: 1) dissolution, hydrolysis of organic compounds, acidogenesis; 2) methanogenesis. The following values of the waste biodestruction coefficients are taken: $k_{1}=$ $1.347 \times 10^{-4}$ year $^{-1}=3.688 \times 10^{-7}$ day $^{-1}-$ is the constant of reactions rate in the phases of the processes of dissolution, hydrolysis of an organic substance and acidogenesis; $k_{2}=0.070$ year $^{-1}=$ $1.917 \times 10^{-4}$ day $^{-1}$ - constant of the reaction rate in the methanogenesis phase; $K=1.7 \times 10^{-3} \mathrm{~m}^{3} / \mathrm{kg}$ - is a coefficient of specific waste capacitance by dissolved substances or the dissolved substances distribution coefficient between the solid and liquid phases. In the calculations, mineralization (salt content) of the concentrate formed after the reverse osmosis desalination can be taken equal to $82 \mathrm{~g} / \mathrm{l}$.

Since the landfill is a flow system, the calculation of the permissible concentrate mineralization $C_{M P C}$ introduced into the landfill body may be implemented by the formula:

$$
C_{M P C}=n\left(C_{c r}-C_{b}\right)+C_{b}
$$

where $n$ - multiplicity of the concentrate dilution in the SDW landfill body; $C_{c r}$ - critical value of the leachate mineralization, $\mathrm{mg} / \mathrm{l} ; C_{b}-$ background mineralization of the leachate before the concentrate introduction into the landfill body, $\mathrm{mg} / \mathrm{l}$.

Substantiation of the $C_{c r}$ critical leachate mineralization is possible through the assessment of the critical salts concentration at which the inhibition of waste components hydrolysis is implemented in the SDW landfill body. The high salt concentration also stops methanogenesis (inhibition by the substrate) and hydrolysis (inhibition by the product).

Inhibitory methanogenesis concentration is 1-6 g/l, hydrolysis and acidogenesis $-10-30 \mathrm{~g} / \mathrm{l}$ (Vavilin et al., 2003). With the values of $30 \mathrm{~g} / \mathrm{l}$ and above, virtually all biodegradation processes stop. Thus, the critical level of leachate mineralization can be estimated by the value of $C_{c r}=30,000 \mathrm{mg} / \mathrm{l}$.

The maximum permissible amount of pollutants $M$, which can be assimilated in the SDW landfill body can be estimated by the formula:

$\mathrm{M}=\mathrm{MPC} . \Delta \tau$

where $\mathrm{M}$ is the maximum permissible weight of the salts that are in the landfill body, kg/ $\mathrm{m}^{2} ; \Delta \tau$ - a time interval during which the leachate mineralization increases in the drainage system after the concentrate introduction is started.

Thus, we formulated a complete conceptual problem statement, which allowed us to form a calculation scheme of the technical object and its mathematical description. Approximated numerical solution of the developed differential equations system of the first order in partial derivatives is implemented in the Mathcad environment by the finite difference method as the most optimal algorithm for solving equations of this class.

\section{RESULTS}

Background mineralization of the leachate, i.e. salt concentration prior to the introduction of the concentrate into the landfill body, is determined both experimentally and by the results of simulation. Mineralization of the leachate collected in the drainage system on the Maryinka SDW landfill amounts to 7,800 mg/l.

The multiplicity of the total dilution of liquid effluents in the filtration flow in the SDW landfill body can be assessed with the formula:

$$
n=\frac{q+\gamma Q_{l}}{q},
$$


where $Q_{1}=0.584 \mathrm{~m}^{3} /\left(\mathrm{m}^{2}\right.$.year $)-$ assessment of the specific value of the leachate flow, $\mathrm{m}^{3} /\left(\mathrm{m}^{2}\right.$.day); $q$ - the volume of the concentrate introduced into the landfill body, $\mathrm{m}^{3} /\left(\mathrm{m}^{2}\right.$.day); $\gamma-$ the mixing coefficient that shows what part of the filtration flow is involved in mixing, with $\gamma=1$.

The multiplicity of the total dilution of liquid effluents in the filtration flow in the SDW landfill body can be assessed with the formula:

$$
n=\frac{k Q_{t}+\gamma Q_{l}}{k Q_{l}}=\frac{k+1}{k}=5.167
$$

where $k=1.2 / 5.0=0.24$ - the concentrate formation coefficient, because from the obtained 5 $\mathrm{m}^{3}$ of the leachate, $q=1.2 \mathrm{~m}^{3} /$ day is directed for burial at the SDW landfill body.

Thus, the maximum permissible mineralization $C_{M P C}$ of the concentrate introduced into the SDW landfill body should not exceed $122,500 \mathrm{mg} / \mathrm{l}$. Exceedance of this level will inevitably lead to the cessation of waste biodegradation in the landfill body, i.e. to the inhibition of methanogenesis, acidogenesis and hydrolysis processes.

Maximum permissible amount of salts $M P C\left(\mathrm{~kg} /\left(\mathrm{m}^{2}\right.\right.$.day $\left.)\right)$, which is allowed to introduce into the SDW landfill body, is estimated by the formula:

$$
M P C=\frac{q C_{\text {LFF }}}{1000}=\frac{k Q_{l} C_{\text {MPC }}}{1000},
$$

where $q$ - the volume of the concentrate, $\mathrm{m}^{3} /\left(\mathrm{m}^{2}\right.$.day); $C_{M P C}-$ maximum permissible mineralization of the $C_{M P C}$ concentrate, $\mathrm{mg} / \mathrm{l}$;

The objective of the first stage is to check the adequacy of forecast estimates of total leachate mineralization if the concentrate is not introduced into the landfill body. The results of computational experiments showed that the Maryinka SDW landfill: 1) is characterized by the nonlinear dynamics of leachate mineralization, asymmetric domed curves and surfaces (Fig. 3); 2) the expected average residence time of the introduced concentrate salts in the waste array is at least 84 days; 3 ) the expected maximum values of leachate mineralization are estimated at 13,000 mg/l; 4) in the second year of operation of the SDW landfill, the estimated mineralization leachate entering the drainage system amounted to 7,800 mg/l.

The consequences of these results are the following conclusions: 1 ) the model takes into account the general dependence of the leachate composition from the time SDW stays in the array of stored waste and moisture; 2) when making precise a forecast for the qualitative characteristics of the leachate it is necessary to take into account the amount of precipitation for the previous period of 3 months; 3) expected limiting values of the leachate COD (chemical oxygen demand) coming from the drainage system are within the range of 2,600 $\mathrm{mg} \mathrm{O}_{2} / \mathrm{l} ; 4$ ) estimated leachate mineralization as a whole correspond to experimental values that correspond to 7,600 mg/l.

The average relative error of the obtained results does not exceed $3 \%$, which is sufficient to solve the tasks of forecasting.

The objective of the second stage is to forecast the total leachate mineralization under the conditions of the concentrate introduction in the landfill body. As a subject of simulation and research, we examined formation and movement processes of contaminated leachate from the surface layers to the drainage system with the infiltration of the concentrate into the body of the Maryinka landfill.

The computational experiment was conducted in two stages: 1) obtaining predictive assessment under the conditions of the controlled introduction of the concentrate into the Maryinka landfill body with the loads which do not reach the maximum permissible levels; 2 ) obtaining predictive assessment under the controlled introduction of the concentrate into the body of the Maryinka landfill with the loads corresponding to the maximum permissible levels.

At the first stage, in the computations we set the conditions that imitate the introduction of a real concentrate into the Maryinka landfill body when the concentrate mineralization amounts to $82 \mathrm{~g} / \mathrm{l}$, i.e. with the loads that do not reach the maximum permissible levels.

The computations confirmed that maximum values of the leachate mineralization (21.9 $\mathrm{g} / \mathrm{l}$ ) after the start of the concentrate introduction did not exceed forecasted critical levels.

The general curve run of leachate mineralization is of an expected nonlinear stepped nature; after the leachate mineralization reaches a maximum it gradually decreases with liquid effluents being continuously introduced into the landfill body. 
The time interval, during which leachate mineralization increases in the drainage system after the start of the concentrate introduction to maximum values $(21.9 \mathrm{~g} / \mathrm{l})$, is estimated by the value of 219 days.

At the second stage, in the computations we set the conditions that imitate the concentrate introduction into the Maryinka landfill body with the loads when the concentrate mineralization amounts to $122.5 \mathrm{~g} / \mathrm{l}$, i.e. with the loads that do not reach the maximum permissible levels.

The computations confirmed that the maximum values of leachate mineralization ( $29.6 \mathrm{~g} /$ l) after the start of the concentrate introduction correspond to the forecasted critical levels, above which virtually complete suppression of biodegradation processes occurs.

The general curve run of leachate mineralization is of an expected nonlinear stepped nature; after the leachate mineralization reaches a

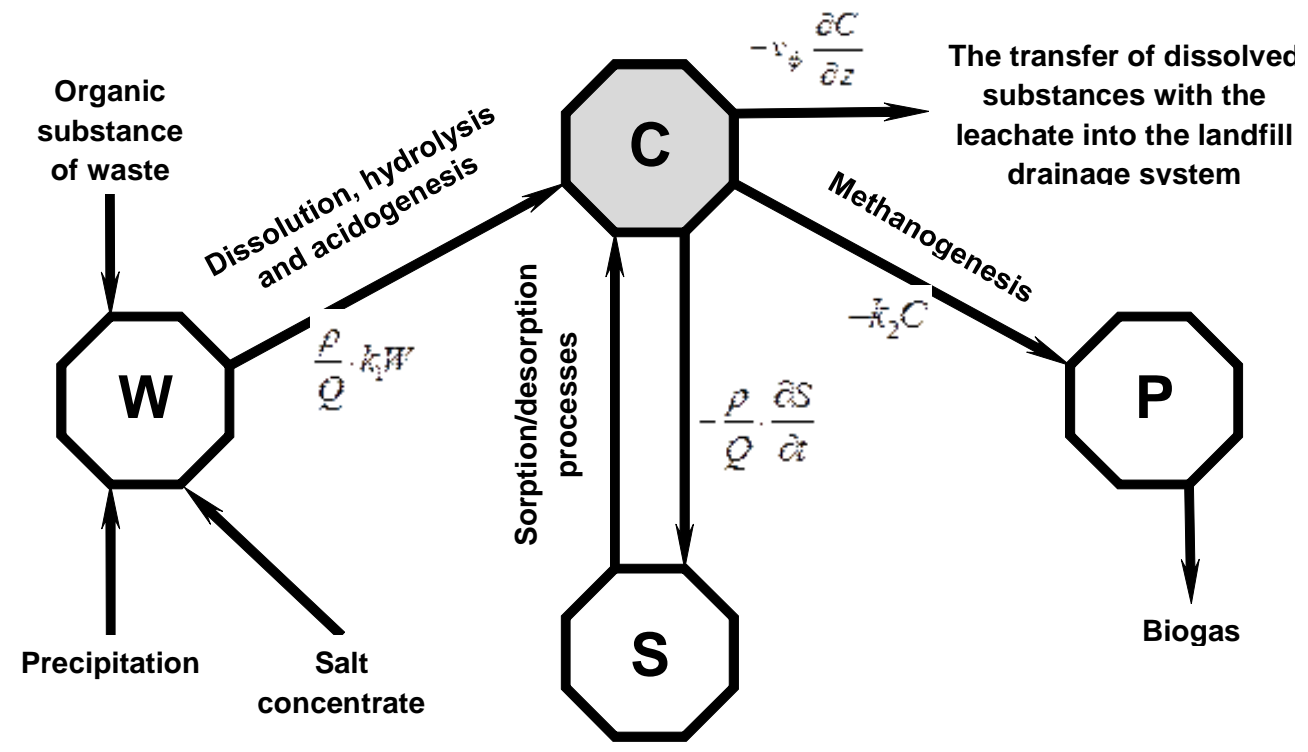

Fig. 1. Simplified kinetic model of waste biodestruction and leachate formation in the landfill body. $\mathrm{C}$-dissolved substances in the liquid phase of the leachate in the ionic and colloidal forms; $\mathrm{S}$ - dissolved substances in the sorbed state in the solid phase of waste; $\mathrm{W}$ - organic substance available for biological destruction and contained in the solid phase of the waste; $\mathrm{P}$ - products of methanogenesis

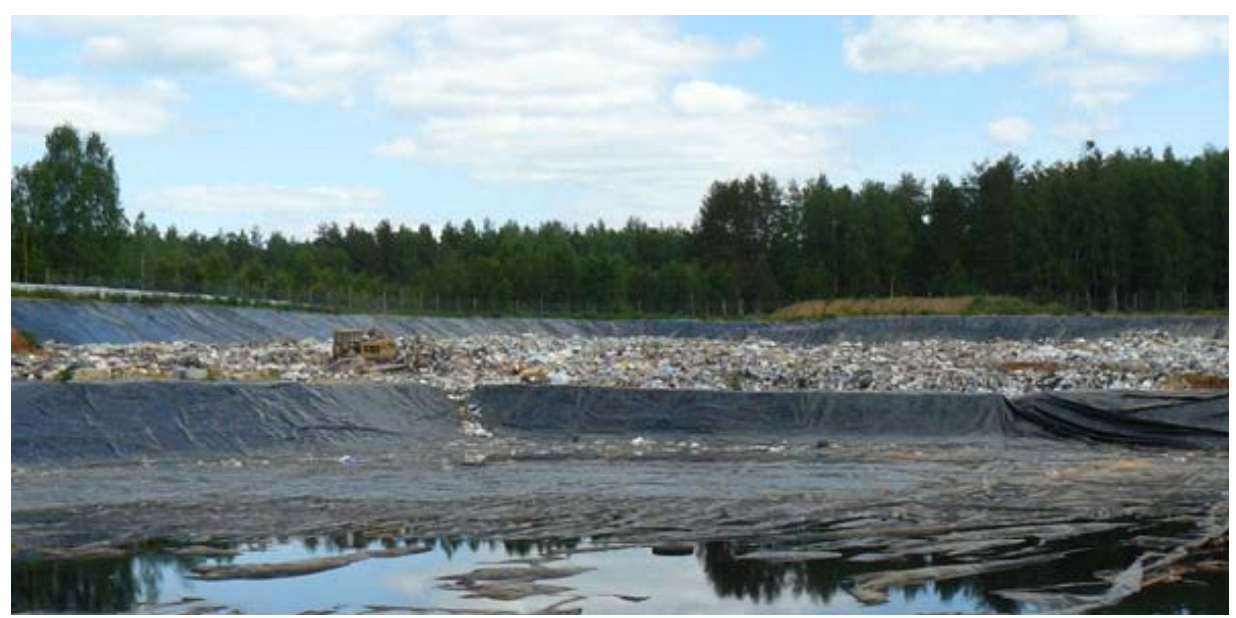

Fig. 2. The layer of waste at the Maryinka SDW landfill 


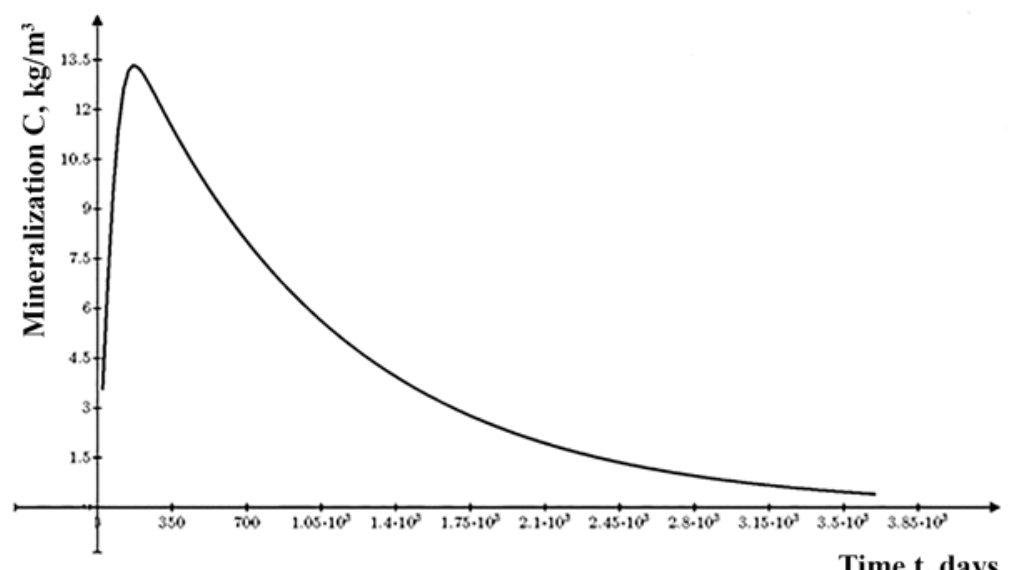

Time t, days

Fig. 3. Mineralization dynamics of the leachate in the drainage system without the concentrate introduction into the landfill body

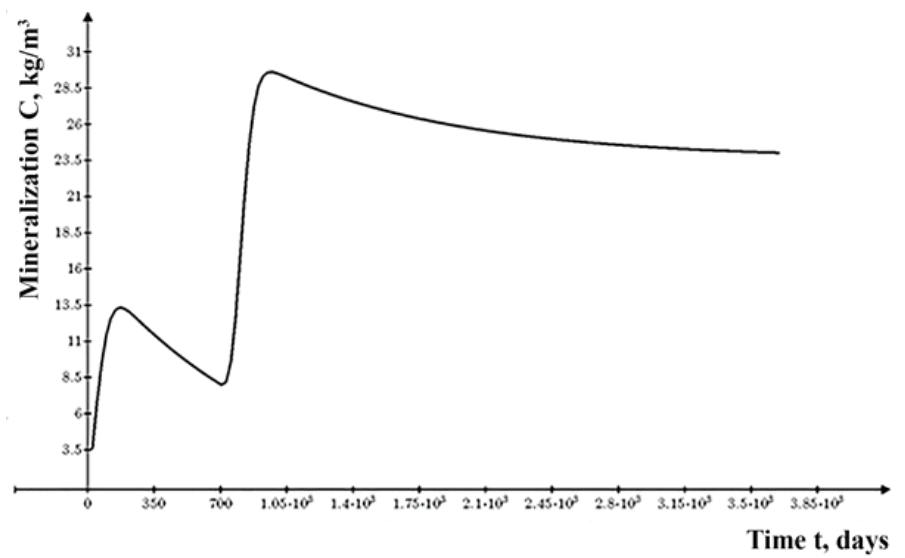

Fig. 4. Leachate mineralization dynamics in the drainage system under the condition of the concentrate introduction into the landfill body with the loads corresponding to the maximum permissible levels

maximum it gradually decreases with liquid effluents being continuously introduced into the landfill body (Fig. 4).

The time interval, during which leachate mineralization increases in the drainage system after the start of the concentrate introduction up to maximum values $(21.9 \mathrm{~g} / \mathrm{l})$, is estimated by the value of 243.3 days.

Inhibition of waste biodegradation and disruption of biological processes that form part of the leachate in the landfill body is regarded as the adverse scenario that occurs as a result of the inhibition by a highly mineralized solution of total mineralization of more than $122.5 \mathrm{~g} / \mathrm{l}$. Hence, the maximum permissible amount of salts and the mass discharge of dry salts allowed for controlled disposal in the Maryinka landfill body is $0.024 \mathrm{~kg} /$ (m².day) or $8.774 \mathrm{~kg} /\left(\mathrm{m}^{2}\right.$.year).

\section{DISCUSSION}

Due to the variety of concurrent physical and chemical, and biological factors that affect the concentration and composition of organic and inorganic contaminants in the SDW landfills leachate, forecasting of the chemical composition of leachate water is a relevant and challenging task. Currently, there is no single approach to forecast the leachate composition, and many models are under development. Existing domestic and foreign computational models allow forecasting the volume of the formed leachate but not its qualitative indicators. 
At the final purification stage of SDW landfill leachate in the process of reverse osmosis separation, the original is divided into two parts the permeate (purified water) and concentrate the flow enriched with salts and that requires further treatment. The concentrate is a brine consisting primarily of chlorides, sulphates, sodium and ammonium bicarbonates. Obviously, the concentrate may be recognized as suitable for controlled disposal in a SDW landfill body, at the same time, the concentrate due to the phenomena of product-substrate biosynthesis regulation can have both inhibitory and stimulatory effects on microbiota, inhibiting or increasing the rate of waste degradation in the landfill.

Suppression of waste biodegradation and disruption of biological processes that form part of the leachate in the landfill body is regarded as the adverse scenario that occurs as a result of the inhibition with the highly mineralized solution of total mineralization of more than $122.5 \mathrm{~g} / \mathrm{l}$. Hence, the maximum permissible amount of salts (the mass discharge of salts based on the dry weight) available for controlled disposal in the Maryinka landfill body is $0.024 \mathrm{~kg} /\left(\mathrm{m}^{2}\right.$ '”day) or $8.774 \mathrm{~kg} /$ ( $\mathrm{m}^{2}$ '”year). The computation of the maximum permissible amount of concentrate is based on the assessment of the critical concentration of salts in the leachate, with which the hydrolysis inhibition of waste components in the landfill body is implemented, as well as on the assimilative capacity of the SDW landfill. Assimilative capacity of the landfill is the landfill body's ability to take a certain mass of substances for a unit of time without disrupting its normal activity, i.e. under the conditions when the critical concentration levels of contaminants in the leachate are not exceeded. The landfill is considered a flow system, the anaerobic bioreactor of continuous operation.

The computational experiment confirmed the projections for the maximum levels of leachate mineralization under the conditions simulating the actual concentrate introduction into the body of the Maryinka landfill with a total mineralization of $82 \mathrm{~g} / \mathrm{l}$. The concentrate is suitable for controlled utilization in the body of a SDW landfill, as after the start of administration, leachate mineralization (21.9 g/l) did not exceed forecasted critical levels and the landfill will not lose its assimilative capacity. The general curve run of leachate mineralization is of an expected nonlinear stepped nature; after the leachate mineralization reaches a maximum it gradually decreases with liquid effluents being continuously introduced into the landfill body.

The results of the computational experiment showed that with the load created by the concentrate on maximum permissible levels, the time interval, during which there is an increase to the maximum values of leachate mineralization in the drainage system after the start of concentrate introduction, amounts to 243.3 days. Therefore, the maximum permissible amount of contaminants (in terms of dry weight), which is assimilated in the body of the Maryinka landfill can be estimated as $5.85 \mathrm{~kg} / \mathrm{m}^{2}$. Assessment of the maximum permissible amounts of contaminants for controlled disposal of liquid effluents in the landfill body must be carried out periodically depending on the stage of landfill life cycle.

We can distinguish the following features of the developed model: 1 ) rather complete reflecti on of the "depth" properties and mechanisms of the "solid phase of waste-leachate" system functioning; 2) account of a large number of variables and parameters of the "solid phase of waste-leachate" system; 3) imitation of the phenomena of various (physical, chemical and ecological) nature; 4) most coefficients of the model have an ecological (physical) sense; 5) demonstrativeness and efficiency of the model; 6) model is developed with the use of both a priori information and experimental data; 7) the opportunity to study holistic characteristics as a set of the "solid phase of waste-leachate" system and to use them as a means of systematic experimentation to forecast the accumulation of salts in the landfill body; 8) the model takes into account the patterns of changes in the leachate composition from the residence time in the SDW landfill body and moisture content; 9) the model can account for seasonal variations in leachate mineralization as result of natural and artificial dilution with precipitation; 10) with limited data for the assessment of chemical, physical and biological factors in the equations, the model's accuracy is acceptable, since the average relative error (deviation) does not exceed 15\%; 11) model allows estimating the maximum permissible intake of liquid effluents for controlled utilization in the landfill body. 


\section{CONCLUSION}

On the example of the Maryinka SDW landfill (the Vladimir Region) under the conditions of the controlled disposal of the concentrate into the landfill body, the predictive assessment of the overall leachate mineralization is given.

1. We estimated the critical level of leachate mineralization, the maximum permissible mineralization of the concentrate, the maximum permissible amount of salts to be disposed in a controlled manner based on dry weight. The computation of the maximum permissible amount of concentrate is based on the assessment of the critical concentration of salts in the leachate, with which the hydrolysis of waste components in the landfill body is inhibited, as well as on the assimilative capacity of the SDW landfill. It is found that the maximum permissible amount of salts (the mass discharge of salts based on the dry weight) available for controlled disposal in the Maryinka landfill body is $0.024 \mathrm{~kg} /\left(\mathrm{m}^{2}\right.$.day) or $8.774 \mathrm{~kg} /\left(\mathrm{m}^{2}\right.$.year).

2. The developed mathematical model is based on the kinematic scheme of biodestruction, which describes the correlation between the structural elements such as: 1) dissolved substances in the liquid phase of the leachate in the ionic and colloidal forms; 2) dissolved substances that passed to the sorbed state in the solid phase of waste; 3) organic substance available for biological destruction and contained in the solid phase of waste; 4) products of methanogenesis. Waste biodestruction in the landfill body is simplistically presented as the process occurring in 2 stages: 1) dissolution, hydrolysis of organic compounds, acidogenesis; 2) methanogenesis.

3. It is found that a concentrate with a total mineralization of up to $122.5 \mathrm{~g} / \mathrm{l}$ can be used for controlled disposal in the Mariyno SDW landfill. Suppression of waste biodestruction and disruption of biological processes that form part of the leachate in the landfill body is an adverse scenario that occurs in case if the critical leachate mineralization level is exceeded.
Suggested mathematical model and dependences related to it have a series of limitations that apply to their use with the purpose of forecasting the increase in the salts content with the concentrate infiltration into the landfill body: 1) the basis of the mathematical model is a simplified biochemical scheme that does not allow giving an accurate forecast of the leachate composition at individual stages of waste biodestruction such as aerobic destruction, hydrolysis, Acidogenesis, active and stable methanogenesis; 2) the model cannot provide an adequate forecast of the landfill assimilative capacity in case if the critical load levels for contaminants are exceeded; 3 ) the model does not consider the effects resulting from the compaction of non-uniform depth in the landfill body as well as the effects created by diffusion and capillary processes in the waste array; not all the components of the SDW landfill water balance are presented clearly.

Analysis of the results of the salt content increase simulation showed that a set of hypotheses formulated at the stage of conceptual and mathematical formulation of the problem is fair and adequate to describe the leachate mineralization in the absence of the concentrate introduction into the landfill body as well as the dynamics of leachate mineralization is completely consistent with the theoretical concepts of SDW waste biodegradation.

\section{ACKNOWLEDGEMENTS}

The work was supported by the Ministry of Education and Science (Agreement of 12.02.2013 No. 02.G25.31.0066).

\section{REFERENCES}

1. Weisman, Ya.I., Chudinov, S.Yu., \& Kravchenko, D.S., Water Balance Management of the SDW Landfill on the Example of the Landfill in Krasnokamsk. Herald of the PNRPU. Urbanistics, 2012; 1: 43-57.

2. Voronkova, T.V., Weisman, Ya.I., \& Chudinov, S.Yu., Recirculation of Leachate at Municipal Solid Waste Landfills. Herald of the PNRPU. Urbanistics, 2012; 3: 83-91.

3. Instructions for the Design, Operation and Reclamation of Landfills for Municipal Solid Waste. Adopted by the Ministry of 
Construction of the Russian Federation, 1996.

4. A Guide to Monitoring Solid Domestic Waste Landfills. Donetsk: TACIS, 2004.

5. Rosenberg, G.S., Shitikov, V.K., \& Brusilovsky, P.M., Ecological Forecasting (Functional Predictors of Time-Series). Togliatti, 1994.

6. Weisman, Ya.I., Korotaev, V.N., \& Tagilov, M.A. (n.d.). The Study on the Chemical Leachate Composition of Disposal Sites of Municipal Solid Waste. Retrieved October 31, 2015, from http:/ /soveko.ru/publications/issledovanie-himsostava-filtrata-objecta-zahoroneniya-tbo.html.

7. Gonopolsky, A.M., Nikolaikina, N.E., Mitashova, N.I., \& Kushnir, K.Ya., Experimental Study on the Leachate Composition of an SDW Landfill and Technology of its Reagent Treatment, 2008. Retrieved October 31, 2015, from //http:/ /incot.ru/www/docs/exh_acc/08_rp/05_s5/ 11_15.pdf

8. Christensen, T.H., \& Kjeldsen, P., Basic Biochemical Processes in Landfills. In T.H. Christensen, R. Cossu, \& R. Stiegmann (Eds.), Sanitary Landfilling: Process, Technology and Environmental Impact. London: Academic Press, 1989.

9. $\quad$ Ehrig, H. J., Quality and Quantity of Sanitary Landfill Leachate. Waste Management \& Research, 1983; 1(1): 53-68.

10. Kostarev, S.I., Faizrakhmanov, R.A., \& Sereda, T.G., Developing an Anaerobic Bioreactor Model for a Municipal Solid Waste Landfill. Ecological Systems and Devices, 2012; 9: 4652.

11. Korolev, S.A., \& Maikov, D.V., Identification of the Mathematical Model and the Study on Various Modes of Methanogenesis in the Mesophilic Environment. Computer Research and Modelling, 2012; 1(4): 131-141.

12. Korolev, S.A., Maikov, D.V., \& Rusyak, I.G. The Study on Stationary Solutions and the Optimization of the Mathematical Methanogenesis Model Parameters. Bulletin of the Tomsk State University, 2012; 3(19): 15 -21.

13. Shevchenko, L.P., \& Shestopalova, O.E., The Study of the Methanogenesis Kinetics of Oil Refining Waste Containing Organic Substances.
Proceedings of the BSTU, 2012; 4: 96-101.

14. Zomarev, A.M., Sanitary-Hygienic Monitoring of the Landfills of Solid Domestic Waste (SDW) on the Stages of a Life Cycle. Abstract of Dissertation for the Degree of Doctor of Medical Sciences. Perm, 2010.

15. Vavilin, V.A., Mathematical Modelling of the Dynamics of Communities of Anaerobic Microorganisms. In Mathematical Modelling in Ecology. Proceedings of the National Conference with International Participation, 1-5 June 2009 2009; 49-50. Pushchino: IPC\&BPSS RAS.

16. Guman, O.M., Ecological and Geological Conditions of Solid Domestic Waste Landfills of the Middle Urals. Abstract of Dissertation for the Degree of Doctor of Geological and Mineralogical Sciences. Yekaterinburg, 2008.

17. Mirny, A.N. (Ed.)., Sanitary Cleaning and Cleaning of Populated Areas: Reference Book (2nd ed.). Moscow: Stroyizdat, 1990.

18. Borzilov, V.A., \& Malakhov, S.G. (Eds.)., Migration of Contaminants in Soils and Adjacent Environments. Leningrad: Hydrometeoizdat, 1989.

19. Trofimov, V.T. (Ed.)., Soil Science. Moscow: Publishing house of the Moscow State University, 2005.

20. Chertes, K.L., Gvozdeva, N.V., Pystin, V.N., Nazarov, V.D., Bykov, D.E., \& Shterenberg, A.M., Treatment of Sewage Sludge of the Oil and Gas Complex. Oil and Gas Business, 2012; 4.

21. Vavilin, V.A., Lokshina, L.Ya., Nozhevnikova, A.N., \& Kalyuzhny, S.V., Landfill as an Excitable Medium. Nature, 2003; 5.

22. Trifonova, T.A., Selivanova, N.V., Shirkin, L.A., Selivanov, O.G., \& Ilyina, M.E., The Problems of Solid Waste Disposal in Landfills. Bulletin of the Samara Scientific Centre of the Russian Academy of Sciences, 2013; 3(15): 885-887.

23. Trifonova, T.A., Altukhova, E.Yu., \& Shirkin, L.A., The Model of Ecotoxicity Formation in Soil under Meadow Vegetation with the Technogenic Pollution of Heavy Metals. Ecological Systems and Devices, 2012; 9: 3542. 